\title{
Effect of oestrogen treatment on clinical and laboratory manifestations of rheumatoid arthritis
}

\author{
J W J BIJLSMA, O HUBER-BRUNING, AND J H H THIJSSEN \\ From the Departments of Rheumatology and Endocrinology, University Hospital Utrecht, The Netherlands
}

\begin{abstract}
SUMmARY The effect of administration of $12.5 \mu \mathrm{g}$ ethinyloestradiol to 10 female patients with active rheumatoid arthritis was investigated in a prospective double blind crossover study. Some improvement during oestrogen treatment was found in $30 \mathrm{~m}$ walking time, haemoglobin concentration, and thrombocytosis. Erythrocyte sedimentation rate (ESR) and $C$ reactive protein (CRP) deteriorated in both periods, but less in the oestrogen period. Grip strength improved during both periods. The number of swollen joints decreased, whereas the joint tenderness score increased during the oestrogen period.
\end{abstract}

Key words: ethinyloestradiol.

Sex hormones are one of the influences on the course of rheumatoid arthritis. It is well known that rheumatoid arthritis has a higher incidence in women. The epidemiological evidence that contraceptive and non-contraceptive female sex hormones decrease the incidence of rheumatoid arthritis in women seems contradictory to this. ${ }^{1}{ }^{2}$ In several models of experimental arthropathy in animals both oestrogenic and androgenic hormones modulate the severity of the arthritis. ${ }^{3+}$ The effect of exogenous sex hormones on the activity of rheumatoid arthritis was studied 20 years ago. The results were conflicting, ${ }^{56}$ and this line of investigation was not explored further.

We have studied the effect of low doses of oestrogens on rheumatoid arthritis in a 24 week prospective double blind crossover study. Some improvement during oestrogen therapy was noted.

\section{Patients and methods}

Ten female patients with adult onset, seropositive, classical (American Rheumatism Association (ARA) criteria) rheumatoid arthritis were admitted to the study. They had active disease shown by at least three of the following characteristics: (a) tenderness of more than six joints; $(b)$ swelling of more than three joints; (c) Ritchie articular index

Accepted for publication 17 April 1987.

Correspondence to Dr J W J Bijlsma. Department of Rheumatology, University Hospital Utrecht. Box 16250. 3500 CG Utrecht. The Netherlands. greater than 20; (d) ESR greater than $35 \mathrm{~mm} / 1 \mathrm{st} \mathrm{h}$; (e) CRP greater than $30 \mathrm{mg} / \mathrm{l} ;(f)$ early morning stiffness of more than 30 minutes. All patients were taking non-steroidal anti-inflammatory drugs, and three patients were taking a slow acting antirheumatic drug (two hydroxychloroquine and one Dpenicillamine). No major changes in treatment were made in the three months before the start of the study. No patient was using prednisone; no contraindication for oestrogen treatment was found in any of the patients.

Seven women were postmenopausal (last menstrual cycle more than one year previously) and three premenopausal. The latter were using nonhormonal contraceptive devices. The age range was 27-68 years with a mean of 55.9 years; the disease duration ranged from one to 35 years with a mean of $16 \cdot 3$ years. All patients were ARA functional class 2. The study design was approved by the Ethical Committee, and the patients gave their informed consent.

Patients were randomly allocated to one of two treatment groups; $12.5 \mu \mathrm{g}$ ethinyloestradiol or placebo was given in three cycles of four weeks (three weeks treatment followed by one 'withdrawal' week), total 12 weeks. This was followed by 12 weeks on the alternative treatment. The three premenopausal women started their treatment on the fifth day of their menses. Afterwards it was known that six women had started with placebo and four with oestrogens.

Assessment included clinical evaluation and blood 
tests at baseline, 12 , and 24 weeks. Clinical evaluation was performed by the same investigator (JWJB) at the same time of day, and both investigator and patient were unaware of the assigned treatment. Clinical evaluation included joint tenderness score and swollen joints score, as described by Ritchie ${ }^{7}$; grip strength measured with the same sphygmomanometer cuff inflated to $30 \mathrm{mmHg}$, wrapped in a standard sleeve (average of three recordings for each hand); and $30 \mathrm{~m}$ walking time.

Blood tests included ESR (Westergren), CRP (nephelometric), haemoglobin concentration, and number of thrombocytes (both by the Coulter counter).

Compliance was measured by the concentration of sex hormone binding globulins (by ammonium sulphate precipitation ${ }^{8}$ ), which increases significantly during oestrogen treatment.

To assess a possible influence of oestrogen treatment the data obtained were analysed based on the percentage changes during 12 weeks treatment (oestrogens $v$ placebo). Statistical differences were calculated by a signed rank test.

\section{Results}

Nine patients completed the study; one women stopped after 22 weeks because of abdominal discomfort due to ovarian cysts. Afterwards it was found that she was first treated with oestrogens and in the second period with placebo. Her data are included in the final assessment.

Two treatment periods were compared: the 'placebo' period (six women the first 12 weeks plus four women the second 12 weeks) and the "oestrogen" period (four women the first 12 weeks plus six women the second 12 weeks).

In Table 1 the mean values and standard errors of the mean of the relevant parameters are given separately at the start of the placebo and of the oestrogen treatment period. Disease activity, as

Table 1. Mean values (and standard errors of the mean) of clinical and laboratory measurements before both treatment periods

\begin{tabular}{lcccc}
\hline & \multicolumn{2}{c}{$\begin{array}{l}\text { Oestrogen } \\
\text { treatment }\end{array}$} & $\begin{array}{l}\text { Placebo } \\
\text { treatment }\end{array}$ \\
\hline Joint tenderness score & $14 \cdot 1$ & $(1 \cdot 7)$ & $14 \cdot 7$ & $(1 \cdot 3)$ \\
Swollen joints score & $6 \cdot 5$ & $(0 \cdot 5)$ & $6 \cdot 8$ & $(0 \cdot 6)$ \\
Grip strength (mmHg) & 52 & $(7)$ & 52 & $(7)$ \\
30 m walking time (s) & $14 \cdot 4$ & $(1 \cdot 4)$ & $13 \cdot 7$ & $(1 \cdot 3)$ \\
ESR (mm/1st h) & $28 \cdot 1$ & $(4 \cdot 0)$ & $29 \cdot 2$ & $(4 \cdot 2)$ \\
CRP (mg/l) & 34 & $(6)$ & 34 & $(6)$ \\
Haemoglobin $(g / l)$ & 94 & $(2 \cdot 0)$ & 97 & $(2 \cdot 0)$ \\
Thrombocytes $\times 10^{-9} / 1$ & 353 & $(18)$ & 365 & $(27)$ \\
\hline
\end{tabular}

Table 2. Mean values (and standard errors of the mean of changes in clinical and laboratory measurements before. and after both treatment periods, given as percentage changes

\begin{tabular}{|c|c|c|c|}
\hline & $\begin{array}{l}\text { Oestrogen } \\
\text { treatment }\end{array}$ & $\begin{array}{l}\text { Placebo } \\
\text { treatment }\end{array}$ & p Value \\
\hline Joint tenderness score & $+26.9(13.2)$ & $+0.6 \quad(5 \cdot 8)$ & $0 \cdot 10$ \\
\hline Swollen joints score & $-1.5(7 \cdot 8)$ & $+11.2 \quad(9.9)$ & $>0 \cdot 50$ \\
\hline Grip strength & $+15 \cdot 0 \quad(5 \cdot 7)$ & $+19.9(10.5)$ & 0.11 \\
\hline $30 \mathrm{~m}$ walking time & $-9.7 \quad(4 \cdot 2)$ & $+3.4 \quad(2 \cdot 5)$ & $0 \cdot(03 *$ \\
\hline ESR & $+20 \cdot 6 \quad(6 \cdot 7)$ & $+39 \cdot 5(21 \cdot 2)$ & $>0.50$ \\
\hline CRP & $+35.5(17 \cdot 3)$ & $+58 \cdot 2(26 \cdot 8)$ & $0 \cdot 08$ \\
\hline Haemoglobin & $+1.9(1.0)$ & $-4 \cdot 4 \quad(1 \cdot 6)$ & $0 \cdot() 4^{*}$ \\
\hline Thrombocytes & $-0.7 \quad(3.5)$ & $+6 \cdot 5 \quad(3 \cdot 7)$ & $0 \cdot\left(03^{*}\right.$ \\
\hline
\end{tabular}

${ }^{*}$ p Values $<0 \cdot 05$; signed rank test.

measured by clinical and laboratory data, was̃ similar at the start of both treatment periods.

As there was a wide variety of disease activity iff the individual patients the changes found are given as percentage changes during both treatmeng periods. These changes are shown in Table 2. Som $\overline{0}$ differences between the placebo and the oestroge treatment periods were then found. Joint tenderness. score increased in the oestrogen period but notoin the placebo period. The swollen joints score creased during placebo treatment but not duxî̀. oestrogen treatment. During both periods grir strength increased. During oestrogen treatment th $\bar{\sigma}$ walking time improved, but worsened during placebo.

The laboratory parameters ESR and CRP in creased during both periods, but more during the placebo period. The haemoglobin concentration and thrombocytosis improved during oestrogen treate ment and worsened during placebo. The improve ments in walking time, haemoglobin concentration and thrombocytosis were statistically significant and point to a beneficial effect of oestrogen treatment? All women showed an increase in sex hormone binding globulins during oestrogen treatment, re flecting treatment compliance.

Some side effects were noted. During oestroge treatment nearly all the postmenopausal wome experienced some subjective signs due to hormonaे treatment; in three women this led to vagina spotting. During follow up for at least six months ng further blood loss was observed. One premenopausad woman stopped two weeks prematurely because of abdominal pain due to ovarian cysts, as described above.

\section{Discussion}

The influence of sex hormones on the various rheumatic diseases is intriguing. Most rheumatio 
diseases have a higher incidence in women. It is thought that women are immunologically more reactive than men and are, therefore, more susceptible to immunologically mediated disorders such as systemic lupus erythematosus (SLE) and rheumatoid arthritis. This is explained by the ability of sex hormones to modulate immune reactivity, with androgens suppressing and oestrogens augmenting this reactivity. ${ }^{9}$ In the clinical situation this seems to hold for SLE, where oestrogens can worsen and androgens can ameliorate disease activity. ${ }^{10} 11$

In contrast with SLE, in rheumatoid arthritis oestrogens seem to have a preventive effect on the incidence of the disease, as shown by epidemiological studies. In addition, there are suggestions that oestrogens can ameliorate disease activity; the disease improves during pregnancy, ${ }^{12}$ in premenopausal women disease activity fluctuates with the menstrual cycle, ${ }^{13}$ and the present study also suggests an ameliorating effect of oestrogens.

In this study we used a low dosage of oestrogens as there are possible risks during long term oestrogen treatment. In four women mild side effects were noted; it thus can be concluded that this low dosage of ethinyloestradiol was biologically active. As progesterone has also been implicated in immunomodulation ${ }^{14}$ we preferred not to use a combination preparation, to prevent confusion in interpretation. In fact four patient groups should be discerned: $(a)$ the patients who were treated with placebo during the first 12 weeks or $(b)$ during the second 12 weeks and $(c)$ the patients who were treated with oestrogens during the first period or $(d)$ during the second period. Unfortunately the number of patients was too small to assess these groups separately. This could bias the results by abating the possible differences.

The duration of the treatment periods was relatively short: 12 weeks. Usually disease modifying antirheumatic drugs have a delayed response, with a possible beneficial effect after more than three months. In our study some improvement had already been noted within three months. Of the eight parameters, five seemed to improve during oestrogen treatment and only one during the placebo period. In addition, two of the three parameters that did not improve during oestrogen treatment deteriorated more during the placebo period. This study in only 10 patients and during a short period suggests that further research in this direction might be fruitful.

At present we can only speculate about the mechanisms involved. A direct interaction between hormones and lymphocytes is likely in view of the presence of oestrogen receptors on human blood mononuclear cells and thymocytes. ${ }^{15}$ The present state of research, however, seems to point to an increase in immune reactivity due to oestrogens. Perhaps this is not true in rheumatoid arthritis, where oestrogens ameliorate disease activity. There are several possibilities that can be considered: $(a)$ the effect of oestrogens is restricted to subsets of lymphocytes, e.g., they affect $\mathrm{T}$ suppressor cells but not $\mathrm{T}$ helper cells; $(b)$ the balance between oestrogens and androgens is different in rheumatoid arthritis compared with SLE, for example; exogenous oestrogens can exert a different influence upon this balance; $(c)$ non-immunological mechanisms, such as the influence of oestrogens on chondrocytes, ${ }^{16}$ have a pivotal role. Clearly more studies in this area are needed.

\section{References}

1 Wingrave S J, Kay C R. Reduction in incidence of rheumatoid arthritis associated with oral contraceptives. Lancet 1978; i: $569-71$.

2 Vandenbroucke J P, Witteman J C M, Valkenburg H A, et al. Non-contraceptive hormones and rheumatoid arthritis in perimenopausal and postmenopausal women. JAMA 1986; 255: 1299-303.

3 Allen J B, Blatter D, Caladra G B, Wilder R L. Sex hormonal effects on the severity of streptococcal cell wall-induced polyarthritis in the rat. Arthritis Rheum 1983; 26: 560-3.

4 Berczi I, Nagy E. Asa S L, Kovacs K. The influence of pituitary hormones on adjuvant arthritis. Arthritis Rheum 1984; 27: 682-8.

5 Blais J A, Demers R. The use of norethylnodrel (Enovid) in the treatment of rheumatoid arthritis (preliminary report) [Abstract]. Arthritis Rheum 1962; 5: 284.

6 Gilbert M. Rotstein J, Cunningham C, Estrin I, Davidson A, Pincus $\mathrm{G}$. Norethylnodrel with mestranol in treatment of RA. JAMA 1964; 190: 235.

7 Ritchie D M, Boyle J A, McInnes J M. et al. Clinical studies with an articular index for the measurement of joint tenderness in patients with rheumatoid arthritis. $Q \mathrm{~J}$ Med 1968; 37: 393-406.

8 Vankammen E. Thijssen J H H, Rademaker B. Schwarz F. The influence of hormonal contraceptives on sex hormone binding globulin capacity. Contraception 1975; 11: 53-9.

9 Fernandes G, Talal N. SLE: hormones and diet. Clin Exp Rheumatol 1986; 4: 183-5.

10 Lahita RG. Sex steroids and the rheumatic diseases. Arthritis Rheum 1985; 28: 121-6.

11 Jungers $P$, Kuttenn $F$, Liote D, et al. Hormonal modulation in systemic lupus erythematosus. Preliminary clinical and hormonal results with cyproterone acetate. Arthritis Rheum 1985; 28: $1243-50$.

12 Ostensen M, Aune B, Husby G. Effect of pregnancy and hormonal changes on the activity of rheumatoid arthritis. Scand J Rheumatol 1983; 12: 69-72.

13 Latman N S. Relation of menstrual cycle phase to symptoms of rheumatoid arthritis. Am J Med 1983; 74: 957-60.

14 Grossman C J. Regulation of the immune system by sex steroids. Endocr Rev 1984; 5: 435-55.

15 Weusten J J A M, Blankenstein M A, Gmelig Meyling F H J, Schuurman H J, Kater L. Thijssen J H H. Presence of oestrogen receptors in human blood mononuclear cells and thymocytes. Acta Endocrinol (Copenh) 1986; 112: 409-14.

16 Mason R M, Lineham J D, Phillipson M A, Black C M. Selective inhibition of proteoglycan and hyaluronate synthesis in chondrocyte cultures by cyclofenil diphenol, a non-steroidal weak oestrogen. Biochem J 1984; 223: 401-12. 